\title{
BAFF selectively enhances the survival of plasmablasts generated from human memory $B$ cells
}

\author{
Danielle T. Avery, ${ }^{1}$ Susan L. Kalled, ${ }^{2}$ Julia I. Ellyard, ${ }^{1,3}$ Christine Ambrose, ${ }^{2}$ \\ Sarah A. Bixler, ${ }^{2}$ Marilyn Thien, ${ }^{1,3}$ Robert Brink, ${ }^{1}$ Fabienne Mackay, ${ }^{4}$ \\ Philip D. Hodgkin, ${ }^{5}$ and Stuart G. Tangye ${ }^{1,3}$ \\ ${ }^{1}$ Centenary Institute of Cancer Medicine and Cell Biology, Newtown, Australia \\ ${ }^{2}$ Department of Immunology and Inflammation, Biogen Inc., Cambridge, Massachusetts, USA \\ ${ }^{3}$ University of Sydney, Sydney, Australia \\ ${ }^{4}$ Department of Arthritis and Inflammation, Garvan Institute of Medical Research, Darlinghurst, Australia \\ ${ }^{5}$ Walter \& Eliza Hall Institute of Medical Research, Royal Melbourne Hospital, Victoria, Australia
}

The generation of Ig-secreting cells (ISCs) from memory B cells requires interactions between antigen-specific (Ag-specific) B cells, $\mathrm{T}$ cells, and dendritic cells. This process must be strictly regulated to ensure sufficient humoral immunity while avoiding production of pathogenic autoantibodies. BAFF, a member of the TNF family, is a key regulator of B cell homeostasis. BAFF exerts its effect by binding to three receptors - transmembrane activator of and CAML interactor (TACI), B cell maturation antigen (BCMA), and $\mathrm{BAFF}$ receptor (BAFF-R). To elucidate the contribution of BAFF to the differentiation of $B$ cells into ISCs, we tracked the fate of human memory $B$ cells stimulated with BAFF or CD40L. BAFF and CD40L significantly increased the overall number of surviving B cells. This was achieved via distinct mechanisms. CD40L induced proliferation of nondifferentiated blasts, while BAFF prevented apoptosis of ISCs without enhancing proliferation. The altered responsiveness of activated memory $B$ cells to CD40L and BAFF correlated with changes in surface phenotype such that expression of CD40 and BAFF-R were reduced on ISCs while BCMA was induced. These results suggest BAFF may enhance humoral immunity in vivo by promoting survival of ISCs via a BCMA-dependent mechanism. These findings have wide-ranging implications for the treatment of human immunodeficiencies as well as autoimmune diseases.

J. Clin. Invest. 112:286-297 (2003). doi:10.1172/JCI200318025.

\section{Introduction}

Several members of the TNF receptor (TNF-R) superfamily play critical roles in humoral immunity by regulating responses of activated B cells. Stimulation of B cells through CD40 is necessary for development of germinal centers, induction of Ig isotype switching, and generation of B cell memory $(1,2)$. Similarly, signals received through CD27 (3), OX40 (4), and TNF-R1 (5) promote human B cell survival, proliferation, and Ig secretion, while CD40induced $\mathrm{B}$ cell activation can be antagonized by CD95 (6) and $\operatorname{CD} 30(7,8)$. Recently, B cell-activating factor belonging to the TNF family (BAFF; also known as BLyS,

Received for publication February 3, 2003, and accepted in revised form May 6, 2003.

Address correspondence to: Stuart Tangye, Centenary Institute of Cancer Medicine and Cell Biology, Locked Bag Number 6, Newtown 2042, New South Wales, Australia.

Phone: 011-61-2-9565-6127; Fax: 011-61-2-9565-6103;

E-mail: s.tangye@centenary.usyd.edu.au.

Conflict of interest: Susan L. Kalled, Christine Ambrose, and Sarah A. Bixler are employees of and stockholders in Biogen Inc. Nonstandard abbreviations used: TNF receptor (TNF-R); systemic lupus erythematosus (SLE); transmembrane activator of and CAML interactor (TACI); B cell maturation antigen (BCMA); BAFF receptor (BAFF-R); antigen (Ag); Ig-secreting cell (ISC); streptavidin-tricolor (SA-TC); 5-(and 6)-carboxyfluorescein diacetate succinimidyl ester (CFSE); IgG, IgA, and IgE (IgG/A/E); $\operatorname{IgM}$ and $\operatorname{IgD}(\operatorname{IgM} / \mathrm{D})$; bone marrow (BM); enzyme-linked immunosorbent spot (ELISPOT).
TALL-1, zTNF4, THANK, and TNFSF13B) (9-12) has emerged as an important regulator of $B$ cell homeostasis. In BAFF-deficient mice, or mice exposed to BAFF-neutralizing agents in vivo, B cell development is severely perturbed (13-15). Conversely, BAFF transgenic mice develop autoimmune diseases resembling human systemic lupus erythematosus (SLE) (16-18) and Sjögren's syndrome (19). Consistent with this has been the finding of elevated serum levels of BAFF in patients with SLE, rheumatoid arthritis, and Sjögren's syndrome (19-21). The mechanism whereby BAFF exerts these effects is by improving survival of peripheral B cells $(22,23)$, which is thought to allow escape of autoreactive $B$ cells to the periphery, leading to autoimmune diseases. Taken together, these findings have led to the proposal that BAFF plays a critical role in maintaining B cell homeostasis, with insufficient signaling by BAFF resulting in $B$ cell immunodeficiency and excessive signaling causing B cell-mediated immunopathology (24).

BAFF exerts its effect by binding three known receptors - transmembrane activator of and CAML interactor (TACI), B cell maturation antigen (BCMA), and BAFF receptor (BAFF-R/BR3) (13, 18, 25-27) - and subsequently eliciting an NF-KB-dependent intracellular signal transduction pathway $(23,25,28,29)$. TACI has been reported to be expressed on resting $B$ cells and a subset of activated $T$ cells (30), while BCMA and BAFF-R 
expression is restricted to $\mathrm{B}$ cells $(13,26,31)$. The contributions of interactions between BAFF and these different receptors to $B$ cell biology appear distinct, however. In BCMA-null mice, no gross affect on B cell development or antigen-specific (Ag-specific) immune responses has been observed $(14,15,32)$. In contrast, mature B cells accumulate in TACI-deficient mice, suggesting TACI may negatively regulate $\mathrm{B}$ cell development (33). Lastly, mice expressing a naturally mutated form of BAFF-R (the A/WySnJ strain) exhibit developmental abnormalities in the $\mathrm{B}$ lineage comparable to those found in BAFF-deficient mice $(26,27,34)$. This raised the notion that the $\mathrm{BAFF} / \mathrm{BAFF}-\mathrm{R}$ interaction is primarily responsible for peripheral B cell survival and development.

While an enormous amount of information regarding the role of BAFF in the developmental pathway of murine $B$ cells has been generated, the effect of BAFF on human $B$ cells and their differentiation remains to be explored. This is particularly important given the potential role BAFF has in the development of human autoimmune diseases (24). By examining the differentiation of human splenic B cells in vitro, we found that BAFF specifically promoted the generation of rapidly-dividing Ig-secreting cells (ISCs) (plasmablasts) from activated memory B cells by enhancing their survival. Consequently, large numbers of effector B cells appeared in cultures containing BAFF. Thus, elevated levels of serum BAFF may contribute to human autoimmune diseases not only by breaking tolerance during B cell development, but also by enhancing plasmablast survival.

\section{Methods}

Reagents. The following Ab's were used: biotinylated antihuman IgM, IgD, IgG, IgA, IgE, anti-hamster IgG, phycoerythrin-anti-CD27 (PE-anti-CD27), FITC, PE-isotype control $\mathrm{mAb}$, rabbit polyclonal anti-active caspase-3 antisera (PharMingen, San Diego, California, USA); FITCanti-CD20, CD27, and PE-anti-CD19 (Becton Dickinson Immunocytometry Systems, San Jose, California, USA). PE- and biotinylated anti-CD38, PE-anti-CD20, biotinylated isotype control $\mathrm{mAb}$, and streptavidin-tricolor (SA-TC; Caltag Laboratories Inc., Burlingame, California, USA); PE-anti-Ki67 (DAKO Australia, Botany, Australia); and PE-conjugated goat polyclonal anti-mouse IgG1 antiserum (Southern Biotechnology Associates, Birmingham, Alabama, USA). Mouse anti-human BAFF-R (clone 9.1), anti-human TACI (clone C4D7), and hamster anti-human BCMA (clone C4E2.2) mAb's were generated by immunizing with receptor-Fc fusion proteins. Soluble myc-BAFF (26) and anti-TACI mAb were biotinylated according to established procedures. To produce a soluble APRIL expression construct, the APRIL gene was amplified from C57BL/6 genomic DNA and ligated to form a cDNA sequence encoding amino acids 105-240 and a $5^{\prime} \mathrm{XhoI}$ site. This fragment was ligated into a modified pcDNA3 vector (Invitrogen Corp., Carlsbad, California, USA) carrying an XhoI site immediately $3^{\prime}$ of an open reading frame encoding an $\mathrm{N}$-terminal secretory signal and FLAG tag. The resulting plasmid was transiently transfected into $\mathrm{CHO}$ cells, and supernatant was collected 3 days later. FLAG-APRIL was purified using an anti-FLAG-agarose column (Sigma-Aldrich, St. Louis, Missouri, USA). Purified FLAG-APRIL bound BCMA and TACI, but not BAFF-R (not shown). Recombinant human CD40L was provided by Marilyn Kehry (Boehringer Ingelheim, Ridgefield, Connecticut, USA). IL-2 was purchased from Endogen Inc. (Woburn, Massachusetts, USA); IL-10 was provided by Rene de Waal Malefyt (DNAX Research Institute, Palo Alto, California, USA); and 5-(and 6)-carboxyfluorescein diacetate succinimidyl ester (CFSE) was purchased from Molecular Probes Inc. (Eugene, Oregon, USA).

Cells. Total human B cells (>98\% CD $19^{+}$) were isolated from normal spleens as previously described (35, 36). Naive and memory B cells were isolated by sorting on a FACStar (Becton Dickinson Immunocytometry Systems) following labeling with FITC-anti-CD20 and PE-anti-CD27 mAb's and collecting CD27-CD20 ${ }^{+}$and $\mathrm{CD} 27^{+} \mathrm{CD} 20^{+} \mathrm{B}$ cells, respectively (37). To isolate IgMexpressing (nonswitched) and isotype-switched memory B cells, total B cells were labeled with anti-CD27 $\mathrm{mAb}$ and a cocktail of $\mathrm{mAb}$ specific for IgG, IgA, and $\operatorname{IgE}(\operatorname{IgG} / \mathrm{A} / \mathrm{E})$ or $\operatorname{IgM}$ and $\operatorname{IgD}(\operatorname{IgM} / \mathrm{D})$, followed by SA-TC (38). Bone marrow (BM) aspirates from normal donors were obtained from the Department of Haematology, Royal Prince Alfred Hospital, Sydney, Australia.

CFSE labeling and B cell cultures. To investigate cell survival, B cells were cultured in media alone or in the presence of BAFF $(2.5 \mu \mathrm{g} / \mathrm{ml})$ or CD40L (1:250 dilution of the membrane preparation). At different times, a known number of CaliBRITE beads (Becton Dickinson Immunocytometry Systems) were added to culture wells prior to harvesting, and the number of viable $B$ cells were calculated as a function of the ratio of beads to live cells (39). To examine the effect of BAFF on B cell differentiation, memory B cells were labeled with CFSE (39) and cultured in 48 -well plates $\left(4 \times 10^{5} / \mathrm{ml}\right.$; Becton Dickinson Labware, Franklin Lakes, New Jersey, USA) for 4 days with CD40L, IL-2 (50 U/ml), and IL-10 (100 U/ml). The cells were harvested, washed, and recultured (approximately $2 \times 10^{5} / \mathrm{ml}$ ) with or without IL-2/IL-10 in the absence or presence of CD 40L or BAFF $(2.5 \mu \mathrm{g} / \mathrm{ml})$ for an additional 4 days $(36,40)$. Primary plasma cells were purified from spleen and $\mathrm{BM}$ by sorting $\mathrm{CD} 38^{++} \mathrm{CD} 20^{+/-}$ cells (41) and then cultured (approximately $5 \times 10^{3} /$ well) in round-bottomed 96 -well plates for 4-5 days. All cultures were performed as described previously (36).

Immunofluorescent staining. For phenotypic analysis, cells were incubated on ice with specific or the appropriate isotype control $\mathrm{mAb}$ and analyzed on a FACScalibur using CellQuest software (Becton Dickinson Immunocytometry Systems). To determine expression of BAFF-Rs on different B cell populations, splenic B cells or BM mononuclear cells were incubated with either mouse anti-human BAFF-R mAb followed by PE-goat anti-mouse IgG1-PE $\mathrm{Ab}$, hamster anti-human BCMA mAb followed by biotinylated anti-hamster Ig mAb, biotinylated BAFF or biotinylated anti-human TACI mAb, and then SA-TC. 
Unoccupied binding sites of the secondary $A b$ were blocked with mouse IgG1, and the cells were incubated with FITC- or PE-anti-CD27 mAb, FITC-anti-CD20 $\mathrm{mAb}$, or PE- or biotinylated anti-CD38 mAb followed by SA-TC. Binding of BAFF to and expression of BAFF-R, $B C M A$, and TACI on different $B$ cell populations were determined by gating on $\mathrm{CD}^{2} 7^{-}$(naive) or $\mathrm{CD} 27^{+}$(memory) B cells (37), or CD38 ${ }^{-}$or $\mathrm{CD} 38^{+} \mathrm{B}$ cells present in in vitro cultures $(36,38,40)$. Expression of Ki67 and active caspase-3 were used to assess cell proliferation (2) and apoptosis (42), respectively, as described previously (36). To assess expression of caspase-3, cells present in both the live and dead populations, defined by scatter plots, were analyzed. According to the manufacturer, the anti-active caspase- $3 \mathrm{Ab}$ detects the same frequency of apoptotic cells as the annexin $V$ binding assay (Pharmingen).

Analysis of Ig secretion. Secretion of IgM, IgG, and IgA was performed using Ig heavy chain-specific ELISA and enzyme-linked immunosorbent spot (ELISPOT) assays as described previously (36).

Statistical analysis. Data were analyzed by ANOVA using Prism software (GraphPad Software for Science Inc., San Diego, California, USA).

\section{Results}

Expression of BAFF-Rs on buman B cells. Human splenic B cells bound soluble BAFF (Figure 1a). An assessment of expression of the currently identified BAFF-Rs BAFF-R, TACI, and BCMA - revealed BAFF-R was highly expressed on human splenic B cells (Figure 1b), while neither TACI (Figure 1c) nor BCMA (Figure 1d) were detected. The specificity of the anti-BCMA and anti-TACI mAb's was confirmed by staining $293 \mathrm{~T}$ cells transiently transfected with plasmids containing the appropriate cDNA (Figure 1, e and f). Thus, the predominant BAFF-binding protein expressed by freshly isolated human B cells is BAFF-R.

$B A F F$ promotes survival of human memory $B$ cells but does not induce proliferation. BAFF can prevent apoptosis of murine B cells $(22,23)$. To extend these studies, human splenic $B$ cells were cultured for 4 days in media alone or with recombinant human BAFF. Under these conditions, BAFF increased cell viability twofold to threefold, as defined by cell recovery at the end of the culture period, compared with unstimulated cultures (Figure 2 , $a$ and $b$ ). When the effect of BAFF on B cell subsets defined by differential expression of CD27 (37) was examined, BAFF consistently promoted survival of memory cells $(2.0- \pm 0.15$-fold increase in cell recovery over unstimulated cultures; mean $\pm \mathrm{SD}, n=3$ ), while its effect on naive $B$ cells was variable (1.4- \pm 0.4 -fold increase; Figure $2 \mathrm{~b}$ ). In contrast, CD40L, a well-known survival factor for human $\mathrm{B}$ cells $(1,2)$, equally enhanced survival of naive and memory $B$ cells (10.7and 7.4-fold increase, respectively, $n=3$; Figure $2 \mathrm{~b}$ ).

The effect of BAFF on proliferation was examined by culturing CFSE-labeled memory B cells for 5 days and then determining the proportion of divided cells (39). Approximately $95 \%$ of unstimulated memory B cells remained undivided during this period (i.e., division 0 ; Figure 2c). In the presence of CD 40L, approximately $40 \%$ of harvested memory $\mathrm{B}$ cells were detected in divisions 1-5 (Figure 2c). In contrast, the distribution of memory $\mathrm{B}$ cells across divisions in BAFF-treated cultures was similar to that in unstimulated cultures, demonstrating that although BAFF enhanced survival of memory B cells, it did not induce their proliferation (Figure $2 \mathrm{c}$ ).

$B A F F$ increases recovery of human memory $B$ cells preactivated with CD40L and IL-2/IL-10. The ability of some factors to influence $\mathrm{B}$ cell responses changes with the activation state of the cells. For instance, resting human B cells respond poorly to stimulation with anti-Ig and IL-4; however, activation with anti-Ig Ab prior to exposure to IL-4 resulted in robust proliferation (43). Similarly, IL-10 can either enhance viability or induce apoptosis of human B cells depending on the time at which activated B cells were exposed to IL-10 (44). Furthermore, although ligation of $\mathrm{CD} 27$ by $\mathrm{CD} 70$ has minimal effect on proliferation of resting B cells (8), culturing activated B cells with CD70-expressing transfectants increased Ig production and the generation of $\mathrm{CD} 38^{+}$plasmablasts in vitro (3). For these reasons, the effect of BAFF on survival of memory $B$ cells preactivated in vitro was examined.

Purified memory cells were first induced to proliferate and differentiate with CD40L and IL-2/IL-10 (40) for 4 days before being washed and recultured for a further 4 days under varying conditions (Figure 3a). These secondary cultures compared the effect of CD40L or BAFF to cultures containing medium only or IL-2/IL-10 (Figure $3 \mathrm{a}$ ). More than $75 \%$ of $\mathrm{B}$ cell blasts died during secondary culture when exposed to media alone, while eightfold more cells were recovered if CD40L was included (Figure 3b). Similarly, BAFF increased cell recovery,
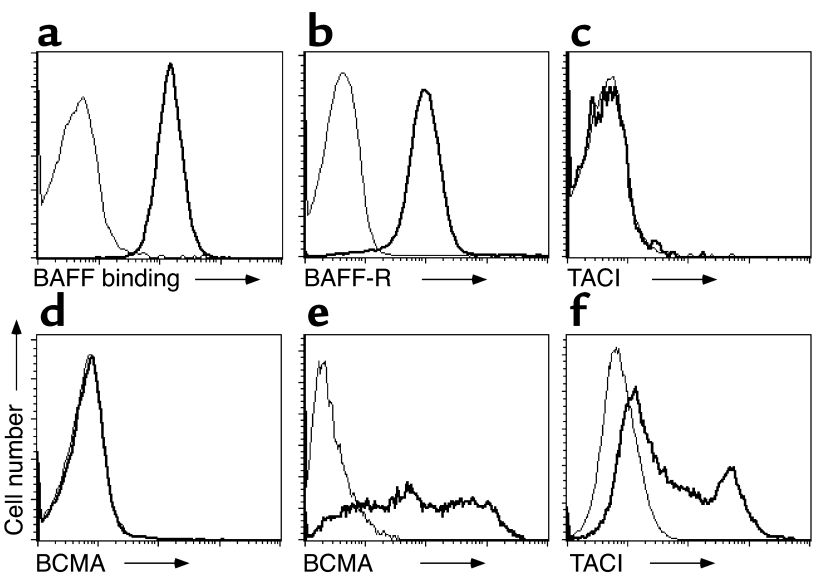

\section{Figure 1}

Expression of BAFF-Rs on human B cells. Human splenic B cells were incubated with (a) soluble BAFF or mAb specific for (b) BAFF-R, (c) $\mathrm{TACl}$, or (d) BCMA. These results represent experiments performed using B cells from three to five different donor spleens. (e and f) 293T cells were transiently transfected with cDNA encoding human (e) $\mathrm{BCMA}$ or $(\mathbf{f}) \mathrm{TACl}$. Expression of the transfected protein was assessed using the anti-BCMA and anti-TACI mAb's described in $\mathbf{c}$ and $\mathbf{d}$. For each plot, the thick and thin lines represent the fluorescence of cells incubated with the specific or control reagent, respectively. 
though to a lesser extent than CD40L (Figure 3b). The inclusion of IL-2/IL-10 in secondary culture also enhanced recovery of cells (compare Figures $3, \mathrm{~b}$ and e), with the level further increased by CD40L or BAFF (Figure $3 e$ ) such that approximately similar numbers of $B$ cells were recovered from these cultures. Thus, although BAFF only had a small effect on survival of resting memory B cells (see Figure 2), its effect was more prominent on preactivated cells where its ability to increase the recovery of cultured B cells approximated that of CD40L.

$B A F F$ preferentially promotes survival of differentiated $C D 38^{+}$ $B$ cells. When human memory $B$ cells are cultured with CD40L and IL-2/IL-10, a population of CD38 ${ }^{+} \mathrm{B}$ cells is generated whose proliferation and survival, in contrast to the CD38- population, becomes independent of further stimulation from CD40L (36). This $\mathrm{CD} 38^{+}$population includes rapidly dividing ISCs $(36,38)$ that resemble plasmablasts (45), while the CD38- population contains some ISCs but predominantly nondifferentiated B blasts $(36,38)$. It was therefore of interest to compare the effect of CD40L and BAFF on the generation of these populations of differentiated $\mathrm{B}$ cells. The proportion of $\mathrm{CD} 38^{+}$ $\mathrm{B}$ cells present in the total $\mathrm{B}$ cell population recovered from secondary cultures containing BAFF or CD40L showed a marked difference, with a greater percentage being found in the presence of BAFF (Figure 3, $c$ and $f$ ). This effect was specific for BAFF because it was abrogated when cultures were performed in the presence of soluble TACI-Ig. Notably, although the overall number of B cells in cultures containing only CD40L exceeded that containing BAFF alone twofold (Figure $3 \mathrm{~b}$ ), a similar number of $\mathrm{CD}^{2} 8^{+}$cells was generated in both of these cultures, and this number exceeded that in unstimulated cultures fivefold (Figure 3d). In cultures containing IL-2/IL-10, 30-fold more CD38 ${ }^{+} \mathrm{B}$ cells were generated than in cultures performed in medium alone (compare Figures 3, d and g). Strikingly, the number of $\mathrm{CD}_{3} 8^{+} \mathrm{B}$ cells was significantly increased (fourfold) in the presence of BAFF compared with IL-2/IL-10 alone (Figure 3g). In contrast to its effect on $\mathrm{CD} 38^{+} \mathrm{B}$ cells, BAFF had no significant impact on the number of $\mathrm{CD} 38^{-} \mathrm{B}$ cells present in the secondary cultures, irrespective of whether IL-2/ IL-10 were present or not, while CD40L significantly increased the number of these cells fivefold to tenfold independently of the cytokines (Figure 3, d and g). Thus, in the presence of IL-2/IL-10, CD40L and BAFF appear to have distinct roles in expanding or maintaining CD38and $\mathrm{CD} 38^{+} \mathrm{B}$ cells, respectively.

$B A F F$ and CD $40 L$ specifically affect the behavior of different populations of activated $B$ cells. In an earlier study, we reported that the generation of $\mathrm{CD} 38^{+} \mathrm{B}$ cells from activated memory $B$ cells increased in frequency with successive cell divisions (36). The distinct roles of CD40L and BAFF in promoting the persistence of $\mathrm{CD}^{-} 8^{-}$and $\mathrm{CD} 38^{+} \mathrm{B}$ cells, respectively, may have been due to a combination of effects on survival, proliferation, or differentiation rate per division. We first examined this in more detail by following the fate of cells with different division histories using CFSE (39). Contour plots of CFSE profiles (showing division) versus CD38 expression of cells recultured with IL-2/IL-10 alone (Figure 4a) or in the presence of CD40L (Figure $4 \mathrm{~b})$ or BAFF (Figure 4c), revealed three populations: CD38- $\mathrm{B}$ cells in early divisions (population 1), CD38$\mathrm{B}$ cells in late divisions (population 2), and $\mathrm{CD} 38^{+} \mathrm{B}$ cells also present in later divisions (population 3; Figure 4). The distribution of these populations, however, differed greatly depending on the activators present in the secondary culture. Specifically, in the presence of IL-2/IL-10, the greatest proportion of cells were
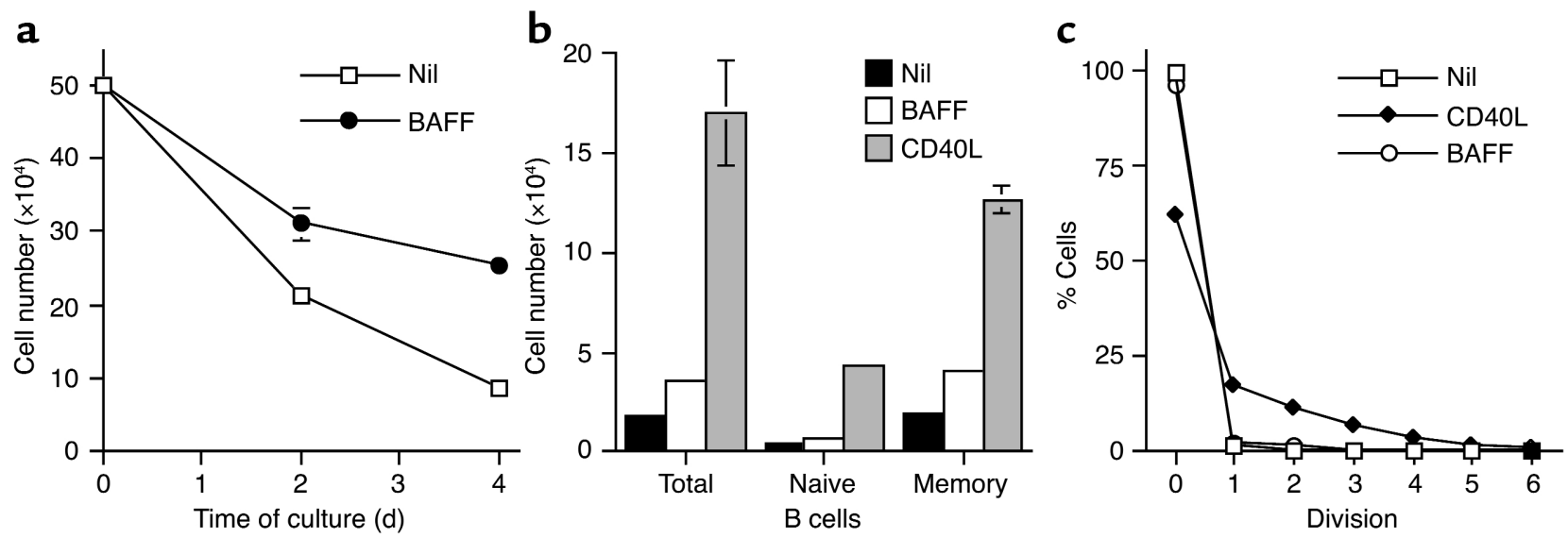

Figure 2

BAFF enhances survival but does not affect proliferation of human B cells. (a) Total splenic B cells were cultured in medium alone (squares) or with BAFF (circles; $2.5 \mu \mathrm{g} / \mathrm{ml}$ ) and the number of viable cells determined after 2 and 4 days. (b) Total, naive, or memory B cells were cultured with media alone (black bars), BAFF (white bars), or CD40L (gray bars), and the number of surviving cells was quantitated after 4 days. Each point represents the mean \pm SD of duplicate samples and is representative of three different experiments. Error bars are shown for all graphs; however, they are not always visible. For the experiment shown, BAFF increased the survival of total, naive, and memory B cells 1.95-, 1.4-, and 2.1-fold, respectively, while CD40L increased survival 9.2-, 9.7-, and 6.3-fold. (c) CFSE-labeled memory B cells were cultured for 5 days with media alone (squares), CD40L (diamonds), or BAFF (circles). The percentage of cells in each division was determined by division slicing. These results are representative of three different experiments. 


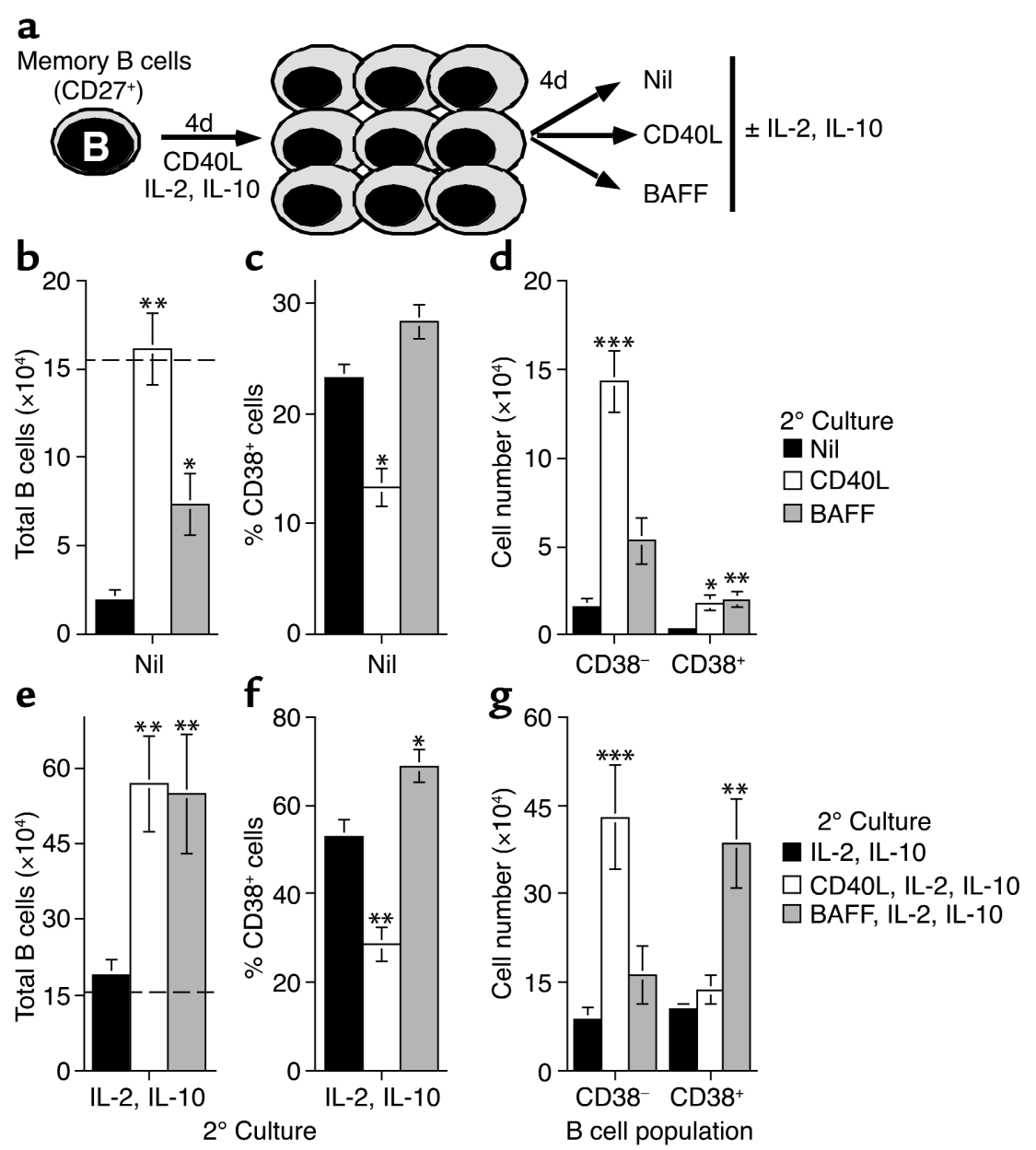

Figure 3

BAFF promotes the generation of $\mathrm{CD}_{3} 8^{+} \mathrm{B}$ cells from activated memory $\mathrm{B}$ cells. (a) The scheme of the two-step culture system used. CFSE-labeled memory B cells were initially cultured with CD40L and IL-2/IL-10 for 4 days, harvested, washed, and then recultured with media (b-d) or IL-2/IL-10 (e-g) alone (black bars) or in the presence of CD40L (white bars) or BAFF (gray bars). After an additional 4 days, the total number of cells ( $\mathbf{b}$ and $\mathbf{e}$ ) and percentage of $\mathrm{CD}_{3} 8^{+} \mathrm{B}$ cells ( $\mathbf{c}$ and $\mathbf{f}$ ) in each culture were determined. The number of CD38and $\mathrm{CD} 38^{+} \mathrm{B}$ cells ( $\mathbf{d}$ and $\mathbf{g}$ ) was calculated by multiplying total cell number by the frequency of $\mathrm{CD} 38^{-}$and $\mathrm{CD} 8^{+}$cells, respectively. The values represent the mean $\pm \mathrm{SEM}$ of four (b-d) or five ( $\mathbf{e}-\mathbf{g})$ experiments. The horizontal lines in $\mathbf{b}$ and $\mathbf{e}$ indicate the mean number of $\mathrm{B}$ cells present at the beginning of the secondary culture. ${ }^{*} P<0.05 ;{ }^{*} P<0.01 ;{ }^{*}{ }^{*} P<0.001$.

Proliferative and antiapoptotic effects of CD $40 \mathrm{~L}$ and BAFF on $\mathrm{CD} 38^{+}$ and $C D 38^{-} B$ cells. The results described above raised the question of the mechanisms responsible for the differential effects of $\mathrm{BAFF}$ and $\mathrm{CD} 40 \mathrm{~L}$ on $\mathrm{CD} 38^{+}$and CD38- B cells. To answer this, the division history of these populations during primary culture with CD40L and IL-2/IL-10 was compared with that of cells recovered from the different secondary cultures. After 4 days of primary culture with CD40L and IL-2/IL-10, only approximately $10 \%$ of $\mathrm{CD} 38$ $B$ cells present remained undivided while the remainder were distributed across divisions 1-6 (Figure $5 \mathrm{a}$; bold line). Following secondary culture with IL-2/IL-10 alone or with BAFF, the division profile of CD38- B cells was similar to that of cells following primary culture (Figure 5a). In the presence of CD40L and IL-2/IL-10, however, CD38- $\mathrm{B}$ cells continued to proliferate as indicated by a marked reduction in the proportion of undivided cells, with the majority of them residing in division 5 (Figure 5a).

When the division history of CD $38^{+} \mathrm{B}$ cells was examined after primary culture, cells were detected in divisions 3-7 (Figure 5b, bold line). In contrast to CD38- $\mathrm{B}$ cells, CD $38^{+} \mathrm{B}$ cells exhibited a proliferative burst on reculture with IL-2/IL-10, which was unaffected by the addition of CD40L or BAFF (Figure $5 \mathrm{~b}$ ). This suggested BAFF may increase the

$\mathrm{CD}^{+} 8^{+}$(population 3), while population 2 was least represented (Figure 4a). In contrast, CD38- B cells present in later divisions (population 2) dominated cultures containing CD40L and IL-2/IL-10 (Figure $4 \mathrm{~b})$. Supplementing cultures with BAFF and IL-2/IL-10 significantly increased population 3 at the expense of population 1, yet had little effect on the relative proportion of population 2 (Figure 4c). Assessment of absolute numbers, rather than proportions, of cells clearly revealed that CD40L and IL-2/IL-10 potently expanded population 2 B cells (13-fold more compared with cytokines alone), while the greatest effect of BAFF was to increase the number of population 3 $\left(\mathrm{CD} 38^{+}\right) \mathrm{B}$ cells (Figure 4d). Thus, CD40L maintains the pool of CD38- $\mathrm{B}$ blasts, while BAFF favors generation of the $\mathrm{CD}^{2} 8^{+}$population, which contains ISCs. recovery of $\mathrm{CD} 38^{+} \mathrm{B}$ cells by improving cell survival. To investigate this possibility, the proportion of apoptotic cells was quantitated by determining expression of active caspase-3 (42) in populations 2 and 3 using an anti-active caspase-3-specific $\mathrm{mAb}$. To demonstrate the specificity of this reagent, the human B cell line Ramos was cultured overnight in the absence of serum to induce apoptosis, after which expression of active caspase- 3 was determined by intracellular staining. Analyzing all cells revealed that $40 \%$ expressed active caspase-3 (Figure $5 c$, thin line). The frequency of active caspase $-3^{+}$cells was reduced to less than $2 \%$ and increased to more than $95 \%$ when only cells present in the live and dead cell gates, respectively, as assessed by light-scatter characteristics, were analyzed (Figure 5c; live, dotted line; dead, bold line). Based on this result, 
all $\mathrm{B}$ cells present in the secondary culture (i.e., live and dead) were included in the analysis. In the presence of IL-2/IL-10, more than $80 \%$ of all population 2 and approximately $70 \%$ of population $3\left(\mathrm{CD}_{3} 8^{+}\right) \mathrm{B}$ cells expressed active caspase-3 (Figure $5 \mathrm{~d}$ ). CD40L significantly reduced the level of apoptosis in CD38- $\mathrm{B}$ cells to less than $35 \%$; it also increased survival of $\mathrm{CD} 38^{+} \mathrm{B}$ cells, although this varied for cells in different experiments (Figure 5d). By contrast, BAFF significantly improved survival of $\mathrm{CD} 38^{+} \mathrm{B}$ cells, but exerted only a modest effect on CD38- $\mathrm{B}$ cells (Figure $5 \mathrm{~d}$ ). Taken together, these data suggest BAFF is a survival factor for $\mathrm{CD} 38^{+} \mathrm{B}$ cells only, while CD40L increases survival of CD38, and occasionally CD $38^{+}$, B cells.

$B A F F$ increases the generation of ISCs. The above experiments revealed BAFF preferentially enhanced survival of $\mathrm{CD}_{3} 8^{+}$plasmablasts generated in vitro. The next step was to determine whether the enhancing effect of BAFF on survival of $\mathrm{CD} 38^{+} \mathrm{B}$ cells led to increased Ig secretion. Reculture with media alone resulted in production of IgM, IgG, and IgA (Figure 6a), the levels of which could be increased five- to tenfold by IL-2/IL-10 (Figure $6 \mathrm{~b}$ ). Addition of BAFF increased Ig production by $B$ cells recultured in the absence and presence of IL-2/IL-10, as did CD40L (Figure 6, a and b). BAFF was shown to cause significant increases in $\operatorname{IgM}$ and $\operatorname{IgA}$ production compared with secondary cultures performed with media or IL-2/IL-10 alone, whereas CD40L significantly increased production of IgA in media-only cultures and IgM in IL-2/IL-10 cultures. In contrast, neither of them led to a significant increase in IgG secretion. This effect on Ig production was specific for BAFF because the amount of IgA produced in secondary cultures containing BAFF and IL-2/IL-10 was reduced in the presence of soluble TACI-Ig to levels observed in cultures containing IL-2/IL-10 only, while IgA production induced by IL-2/IL-10, with or without CD40L, was unaffected (Figure 6c).

It was next determined whether the increased production of Ig observed in the presence of BAFF reflected an increase in the number of ISCs or an increase in the amount of Ig produced per cell. For these experiments, preactivated memory $B$ cells were recultured with IL-2/IL-10 alone or in the presence of BAFF for an additional 3 days. ELISPOT assays were then performed on the whole population of viable cells. The proportion of ISCs was increased from $32.8 \%$ in the presence of IL-2/IL-10 to $45.4 \%$ in the presence of BAFF and IL-2/ IL-10. Importantly, the absolute number of ISCs in secondary cultures containing BAFF and IL-2/IL-10 was increased more than twofold compared with cultures containing only the cytokines (Figure 6d). The most striking effect of BAFF was on the generation of IgA ISCs. In the two experiments performed, BAFF in combination with IL-2/IL-10 increased IgA-secreting cells 7.3- and 4.4-fold compared with IL-2/IL-10 alone, while its effect on cells secreting the other Ig isotypes was approximately twofold (Figure $6 \mathrm{~d}$ ). Thus, the increased Ig production occurring in the presence of BAFF results from an increase in the number of effector ISCs, rather than an increased rate of production of Ig by ISCs.

Elevated levels of IgA in secondary cultures containing BAFF could have resulted from expansion of IgA-expressing $B$ cells present in the memory population or induction of Ig isotype switching by nonswitched $\operatorname{IgM} / \mathrm{D}^{+}$ memory B cells, which comprise a significant population of the total splenic memory $B$ cell population $(35,38)$. To examine this, switched and nonswitched memory B cells
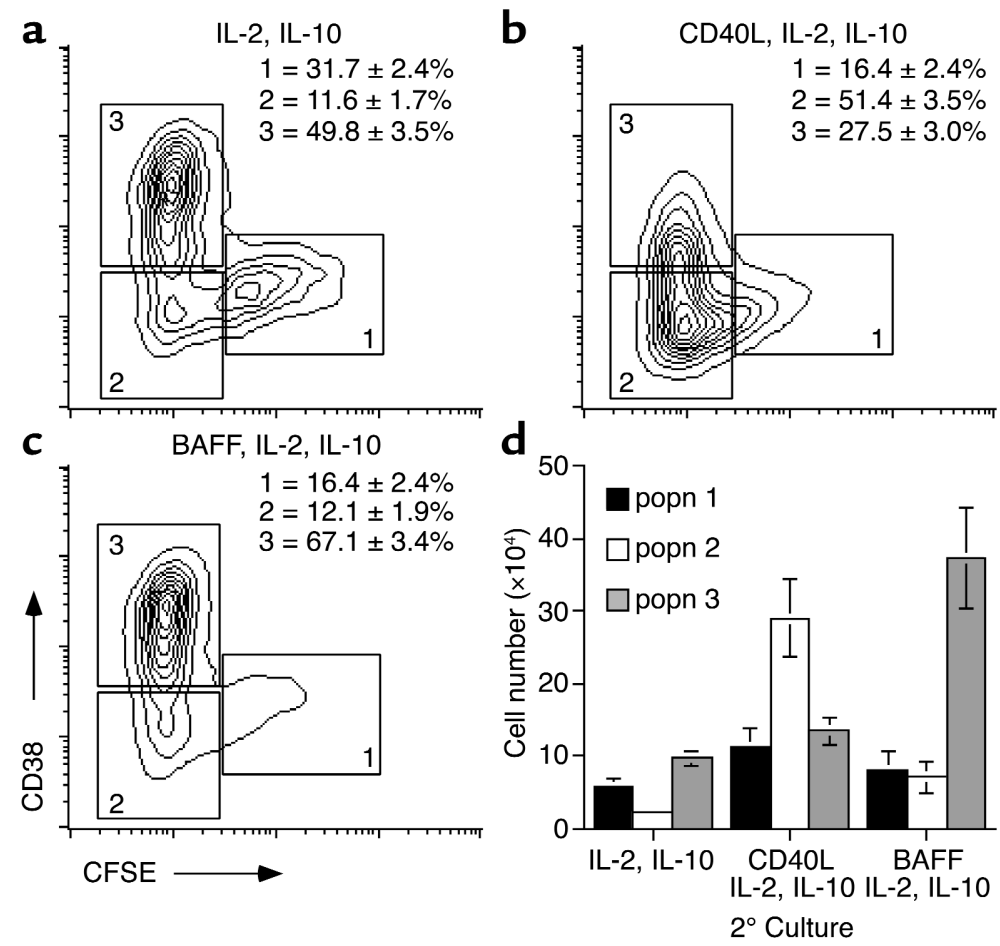

\begin{abstract}
Figure 4
Differential effect of CD40L and BAFF on the generation and maintenance of populations of activated memory $B$ cells. CFSE-labeled memory $B$ cells were cultured with CD40L and IL-2/IL-10 for 4 days, washed, and then recultured for an additional 4 days with (a) IL-2/IL-10, (b) CD40L and IL-2/IL-10, or (c) BAFF and IL-2/IL-10. After the secondary culture, cell populations defined by CFSE dilution and CD38 expression were determined. Population (popn.) 1: undivided early divisions/CD38-; population 2: late divisions/CD38-; population 3: late divisions $/ C D 38^{+}$. The values represent the mean percentage of cells $( \pm$ SEM of seven independent experiments) comprising populations 1, 2, and 3. (d) The absolute number of cells present in populations 1 (black bars), 2 (white bars), and 3 (gray bars) in secondary cultures containing IL-2/IL-10, CD40L and IL-2/ IL-10, or BAFF and IL-2/IL-10 was determined by multiplying the total cell number by the frequency of cells, using the gates illustrated in a-c. Each value represents the mean \pm SEM of five independent experiments.
\end{abstract}


were isolated and then cultured according to the scheme illustrated in Figure 3a. Reculture with IL-2/IL-10 alone resulted in production of low but detectable amounts of IgA from IgM-expressing memory B cells (Figure 6e), while substantially more IgA was produced by switched $\mathrm{IgG} / \mathrm{A} / \mathrm{E}^{+}$memory B cells (Figure $6 \mathrm{f}$ ). Addition of CD $40 \mathrm{~L}$ caused an approximately twofold increase in IgA production by both populations of $\mathrm{B}$ cells (Figure 6 , $\mathrm{e}$ and $\mathrm{f}$ ). BAFF led to a much greater increase in IgA production by switched memory B cells (Figure 6f), however. Thus, the majority of IgA secreted by total memory B cells in response to BAFF stimulation is likely to be derived from isotype-switched memory B cells.

Our previous studies demonstrated that ISCs were present in both the CD38- and $\mathrm{CD} 38^{+}$populations of divided $B$ cells (populations 2 and 3; ref. 36). Thus, the effect of BAFF on Ig secretion by these different subsets was examined by sort-purifying B cells corresponding to populations 2 and 3 and reculturing them for an additional 2 days with IL-2/IL-10 in the absence or presence of CD40L or BAFF. Although the amount of IgA produced by $\mathrm{CD} 38^{-} \mathrm{B}$ cells was unaffected by either
CD40L or BAFF (Figure $6 \mathrm{~g}$ ), secretion by $\mathrm{CD} 38^{+} \mathrm{B}$ cells was consistently augmented by BAFF ( 1.53 -fold \pm 0.07 fold increase, $n=3$; Figure $6 \mathrm{~g}$ ). The differential sensitivity of $\mathrm{CD}^{-} 8^{-}$and $\mathrm{CD} 38^{+}$ISCs to BAFF resulted in secretion of up to four times more IgA by $\mathrm{CD} 38^{+} \mathrm{B}$ cells compared with $\mathrm{CD}^{-} \mathrm{B}$ cells (Figure 6g). Thus, although $\mathrm{CD}^{-} 8^{-}$and $\mathrm{CD} 38^{+} \mathrm{B}$ cells both produced $\mathrm{IgA}$, BAFF appeared to specifically enhance the function of ISCs within the $\mathrm{CD} 38^{+}$population.

Activated $B$ cells alter expression of BAFF-Rs during differentiation to $\mathrm{CD} 38^{+} \mathrm{B}$ cells. Expression of BAFF-R, TACI, and BCMA by activated $B$ cells was investigated next to determine whether the selective sensitivity of $\mathrm{CD}^{-}{ }^{-}$and $\mathrm{CD} 38^{+} \mathrm{B}$ cells to BAFF resulted from differential expression of the various BAFF-Rs. Due to the disparate sensitivity to CD40L exhibited by these cells for their continued expansion and survival (Figure 5), expression of CD40 was also determined. For this analysis, cultures of activated B cells were divided into populations 1, 2, and 3 (see Figure 4). BAFF was shown to bind all three populations, although binding to population 3 was reduced relative to populations 1 and 2 (Figure 7a). The
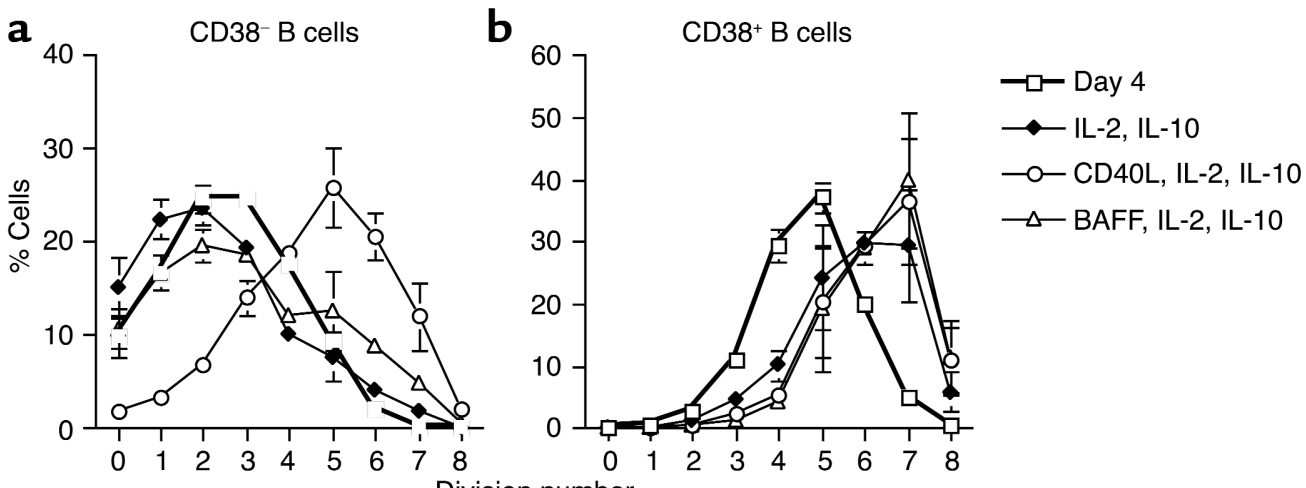

C
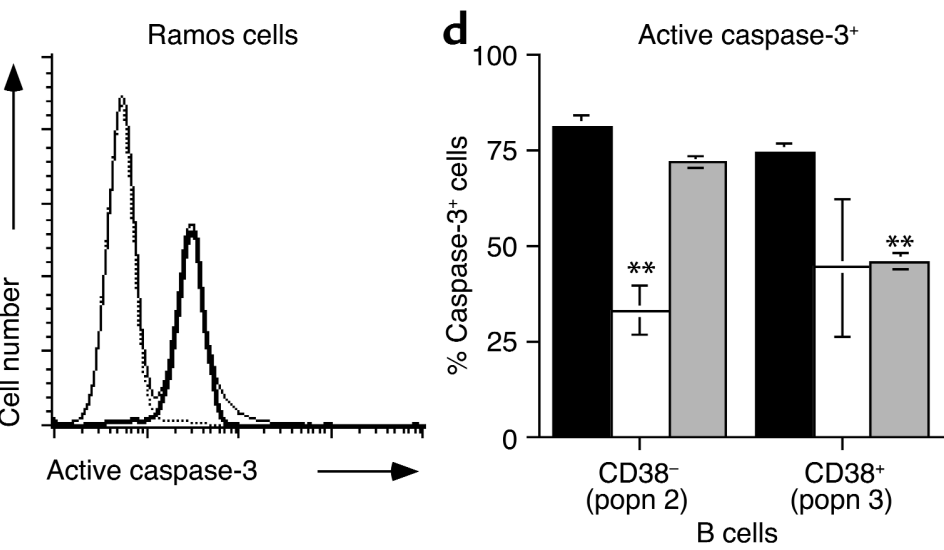

IL-2, IL-10

$\square$ CD40L, IL-2, IL-10

BAFF, IL-2, IL-10

\section{Figure 5}

CD40L and BAFF have distinct effects on proliferation and survival of CD38- and CD38 ${ }^{+} \mathrm{B}$ cells. CFSE-labeled memory B cells were cultured as described in Figure 3a. The percentage of (a) CD38- and (b) CD38 ${ }^{+}$B cells present in different divisions after primary culture (day 4; thick line, squares) or following secondary culture with IL-2/IL-10 (diamonds), CD40L and IL-2/IL-10 (circles), or BAFF and IL-2/IL-10 (triangles) was determined by division slicing. Each value represents the mean \pm SEM of five different experiments. (c) Ramos B cells were cultured overnight in the absence of serum. Expression of active caspase-3 by total cells (thin line), live cells (dotted line), and dead cells (bold line) was then determined by intracellular staining and flow cytometry using gates established according to forward-and side-scatter characteristics. (d) The percentage of populations 2 and $3 \mathrm{~B}$ cells expressing active caspase- 3 following secondary culture with IL-2/IL-10 (black bars), CD40L and IL-2/IL-10 (white bars), or BAFF and IL-2/IL-10 (gray bars) was determined as described for $\mathbf{c}$ by gating on both live and dead cells. Each value represents the mean \pm SEM of three different experiments. ${ }^{*} P<0.01$. 

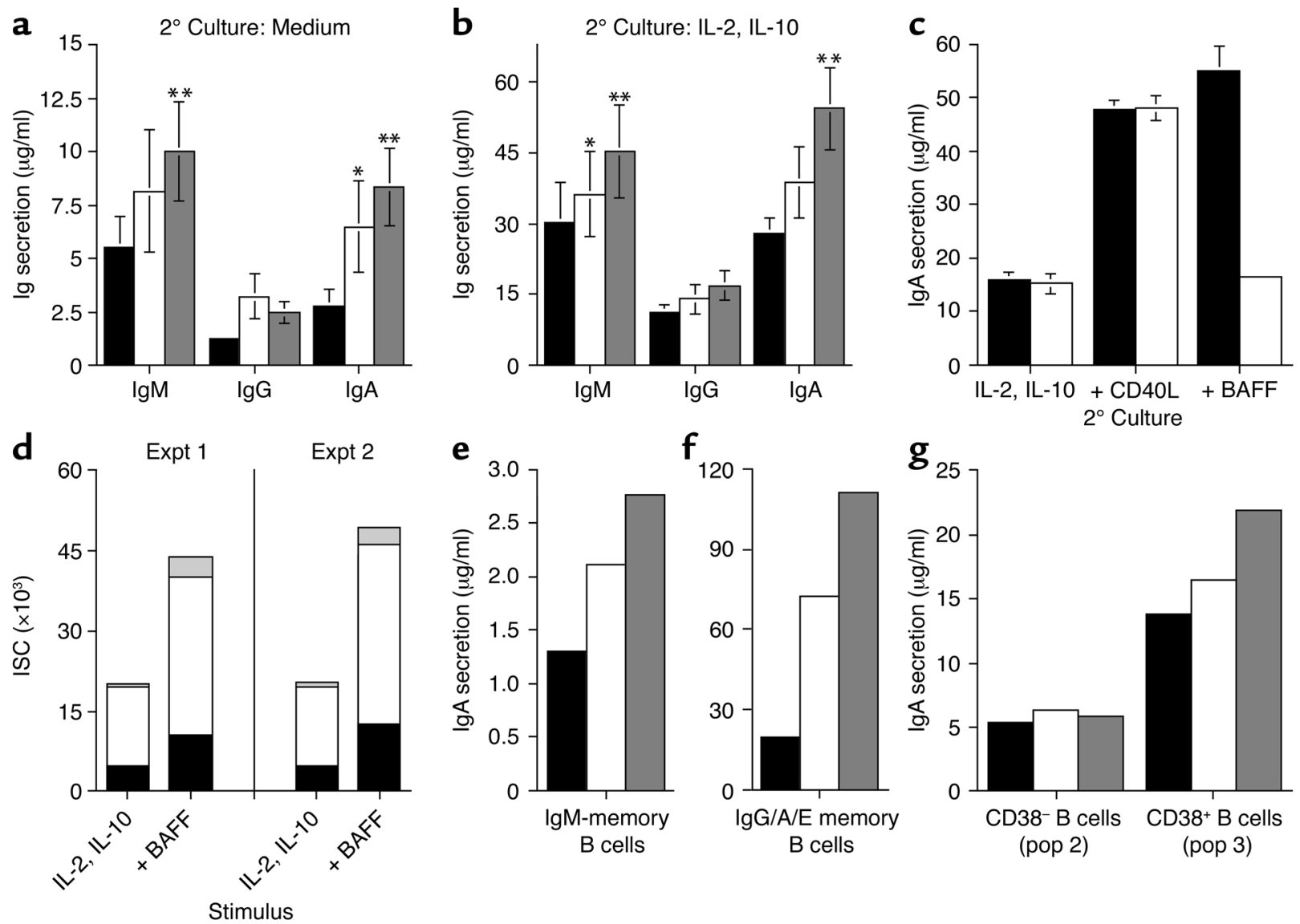

\section{Figure 6}

BAFF increases the generation of ISC from activated memory B cells. (a and $\mathbf{b}$ ) Memory B cells were preactivated with CD40L and IL-2/IL-10 for 4 days and then recultured with (a) media (black bars), or (b) IL-2/IL-10 alone (black bars) or in the presence of CD40L (white bars) or BAFF (gray bars). Each value represents the mean Ig secretion \pm SEM of five (a) or seven (b) experiments using cells from different donors. ${ }^{*} P<0.05$; ${ }^{*} P<0.01$. (c) Secondary B cell cultures were performed in the absence (white bars) or presence (black bars) of soluble TACl-lg $(20 \mu \mathrm{g} / \mathrm{ml})$. The values represent the mean $\operatorname{lgA} \pm$ SD of duplicate samples. (d) Memory B cells were preactivated with CD40L/IL-2/IL-10 for 4 days and then recultured with IL-2/IL-10 alone or in the presence of BAFF. The total number of cells secreting IgM (black bars), IgG (white bars), and IgA (gray bars) was determined by ELISPOT. Expt, experiment. (e) $\operatorname{lgM}{ }^{+}$and $(\mathbf{f}) \operatorname{IgG} / \mathrm{A} / \mathrm{E}^{+}$memory $\mathrm{B}$ cells were isolated by cell sorting, and the amount of IgA secreted during secondary culture with IL-2/IL-10 (black bars), CD40L/IL-2/IL-10 (white bars), or BAFF/IL-2/IL-10 (gray bars) was determined. The scales of the $y$ axes of these graphs are different to enable meaningful comparison. (g) Cells corresponding to populations 2 and 3 were isolated by sorting, recultured with IL-2/IL-10 (black bars), CD40L/IL-2/IL-10 (white bars), or BAFF/IL-2/IL-10 (gray bars), and the amount of IgA secreted was then determined.

phenotype of undivided CD38- B cells (population 1) was similar to freshly isolated memory B cells (see Figure 1), with these cells expressing BAFF-R and CD40, but not TACI or BCMA (Figure 7, left panel). Population $2 \mathrm{~B}$ cells were heterogeneous for expression of BAFF-R and CD40, with some cells downregulating expression of both receptors, while TACI remained very low and BCMA weak but detectable (Figure 7, middle panel). By contrast, the majority of $\mathrm{CD} 38^{+} \mathrm{B}$ cells (population 3) lost expression of BAFF-R, while the levels of CD40 were uniformly reduced more than tenfold compared with population 1 (Figure 7, right panel). Importantly, expression of BCMA was further increased compared with population 2 (Figure $7 \mathrm{~d}$, right panel). Thus, although $\mathrm{CD} 38^{+} \mathrm{B}$ cells retain the ability to bind BAFF (Figure 7a), the receptors responsible for this interaction appear to differ from those used by resting memory $\mathrm{B}$ cells. It is therefore possible that the effect of BAFF on $\mathrm{CD}_{3}{ }^{+} \mathrm{B}$ cells is mediated through the acquired expression of BCMA as well as residual expression of BAFF-R. APRIL, a bomologue of BAFF, also promotes survival of buman ISCs. The amino acid sequence of BAFF exhibits greatest homology with APRIL $(9,24)$. These two ligands both bind TACI and BCMA with similar affinities; however, only BAFF binds BAFF-R $(15,24,26)$. We hypothesized that if BAFF increased survival of $\mathrm{CD} 38^{+}$ISCs by interacting with BCMA, this effect would be duplicated by APRIL. In contrast, if this effect resulted from BAFF binding residual BAFF-R on CD38 ${ }^{+} \mathrm{B}$ cells (Figure $7 \mathrm{~b}$ ), APRIL would not substitute for BAFF. This was examined by performing secondary cultures in the presence of IL-2/IL-10 alone or with CD40L, BAFF, or mouse APRIL (which can also bind human BCMA; refs. 15, 26). Compared with IL-2/IL-10 alone, both BAFF and APRIL 


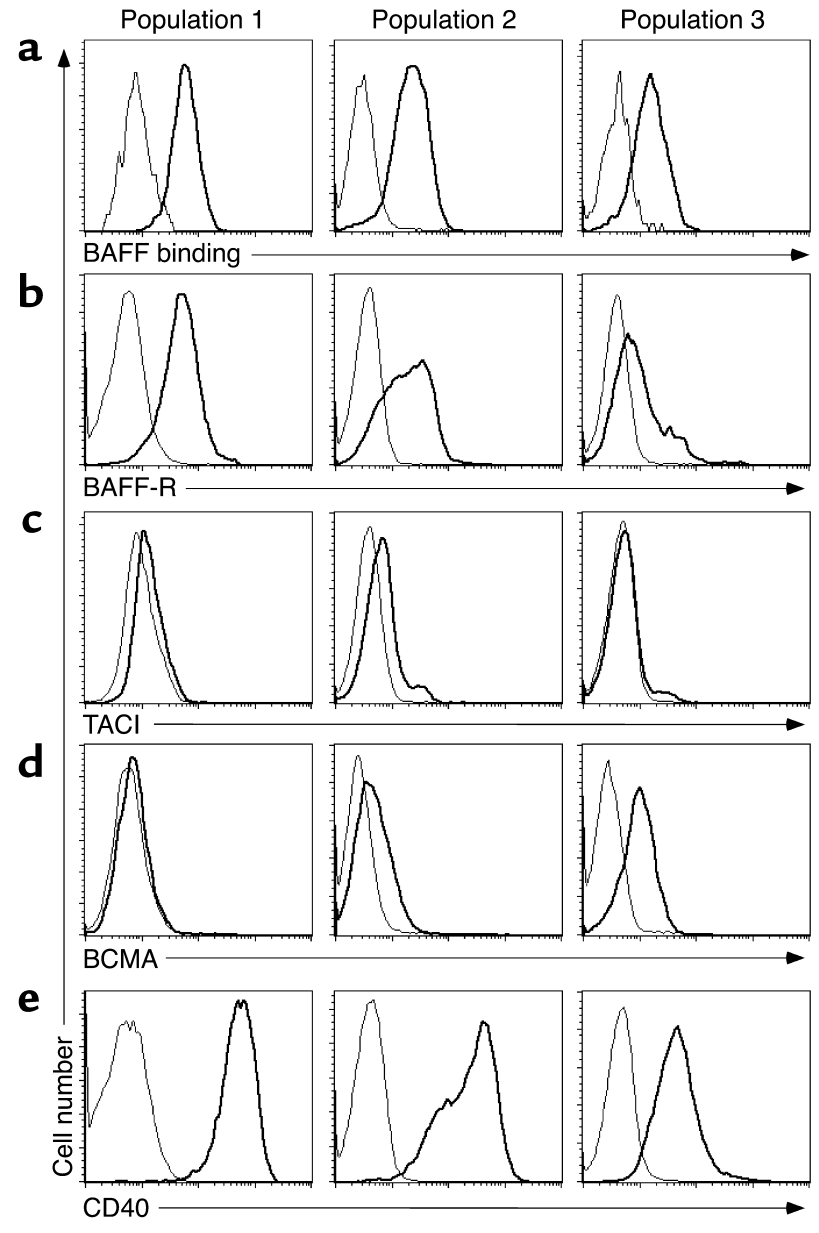

increased the number of $\mathrm{CD} 38^{+} \mathrm{B}$ cells and secretion of IgA by threefold (Figure 8 , a and $\mathrm{b}$ ), as well as the proportion of $\mathrm{CD}^{3} 8^{+} \mathrm{B}$ cells (population 3 ) by $25-40 \%$. These data therefore suggest BCMA induced on $\mathrm{CD} 38^{+} \mathrm{B}$ cells is functional and is responsible for mediating BAFFinduced survival of ISCs rather than residual BAFF-R.

Function of BAFF-Rs on in vivo-generated ISCs. The ability of BAFF to increase Ig secretion by $\mathrm{CD} 38^{+} \mathrm{B}$ cells generated in vitro suggested it may have a similar role on primary plasma cells. The high rate of proliferation of in vitro-generated $\mathrm{CD} 38^{+} \mathrm{B}$ cells indicated these cells resembled plasmablasts, however, rather than terminally differentiated nondividing plasma cells (Figure 5) $(36,38)$. To identify the developmental stage at which BAFF may act to increase Ig secretion in vivo, primary $\mathrm{CD} 38^{++} \mathrm{CD} 20^{+/-}$cells at distinct stages of differentiation were used (Table 1). In experiment 1 , the splenic $\mathrm{CD} 38^{++} \mathrm{CD} 20^{+/-}$population contained predominantly plasmablasts, as revealed by expression of the proliferation-associated antigen Ki67 by more than $90 \%$ of these cells, while the same subset of cells derived from another spleen (experiment 2) or BM (experiment 3) was more akin to terminally differentiated plasma cells $\left(<1 \% \mathrm{Ki} 67^{+}\right.$, Table 1$)$. Total $\mathrm{CD} 38^{++} \mathrm{CD} 20^{+/-}$cells secreted detectable amounts of $\operatorname{IgM}$, IgG, and IgA in the presence of IL-2/IL-10 (Table 1). Following addition of

\section{Figure 7}

Altered expression of BAFF-Rs and CD40L on activated human B cells. CFSE-labeled memory B cells were cultured as in Figure $3 a$. Cells were harvested and incubated with anti-CD38 mAb in combination with (a) soluble BAFF or mAb specific for (b) BAFF-R, (c) TACI, (d) BCMA, or (e) CD40. Expression of these receptors on $B$ cells in populations 1 (left panel), 2 (middle panel), and 3 (right panel) was determined. For each plot, the thick and thin lines represent the fluorescence of cells incubated with the specific or isotype control $\mathrm{mAb}$ or protein, respectively. These results are representative of three independent experiments.

BAFF to plasmablasts, Ig secretion was increased approximately twofold, compared with cultures containing cytokines alone (Table 1 , experiment 1 ). BAFF exerted relatively little effect on Ig secretion by fully differentiated plasma cells (Table 1, experiments 2 and 3 ), however. Interestingly, plasmablasts tested in experiment 1 exhibited higher levels of expression of BCMA than plasma cells from the other donors, while expression of BAFF-R on all CD $38^{++} \mathrm{CD} 2 \mathrm{O}^{+/-} \mathrm{B}$ cells was extinguished (data not shown). Thus, the data derived from examining Ig secretion by in vitro-generated and in vivo-derived $\mathrm{CD} 38^{++} \mathrm{CD} 2 \mathrm{O}^{+/-} \mathrm{B}$ cells suggest the effect of BAFF is restricted to plasmablasts, which retain the capacity to divide, rather than terminally differentiated nondividing plasma cells.

\section{Discussion}

BAFF has emerged as a major regulator of murine $B$ cell homeostasis (24). Our results extend the knowledge of BAFF not only to its functions in the later stages of B cell differentiation, but also to humans. BAFF was found to improve survival of human memory B cells in vitro without inducing cell division, consistent with its antiapoptotic and nonmitogenic effects reported previously for murine B cells $(22,23)$. The ability of BAFF to increase survival was particularly apparent in cultures of memory

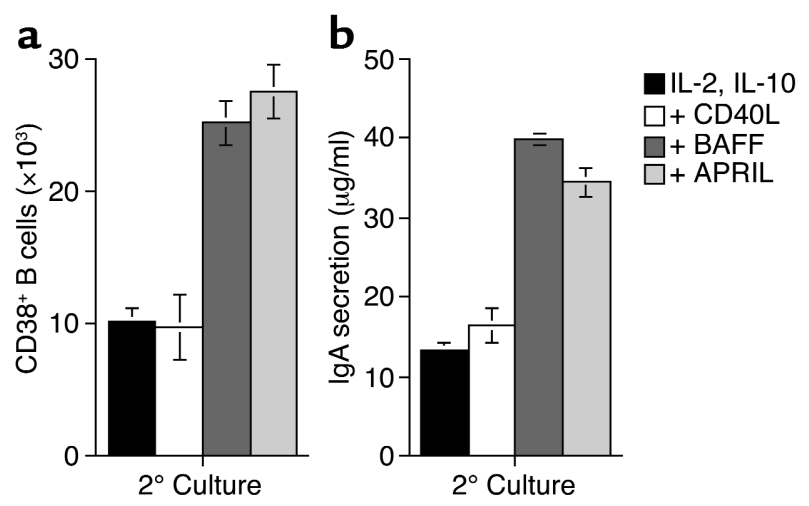

\section{Figure 8}

APRIL and BAFF are equally efficient at increasing survival of human ISCs. Memory B cells were cultured with CD40L and IL-2/IL-10 for 4 days, washed, and then recultured for an additional 4 days with IL-2/ IL-10 alone (black bars) or in the presence of CD40L (white bars), BAFF (dark gray bars), or APRIL (light gray bars; $500 \mathrm{ng} / \mathrm{ml}$ ). The (a) number of $C D 38^{+} B$ cells and (b) secretion of IgA was then determined. Each value represents the mean \pm SD of duplicate samples. 
Table 1

Effect of BAFF on Ig secretion by primary plasma cells

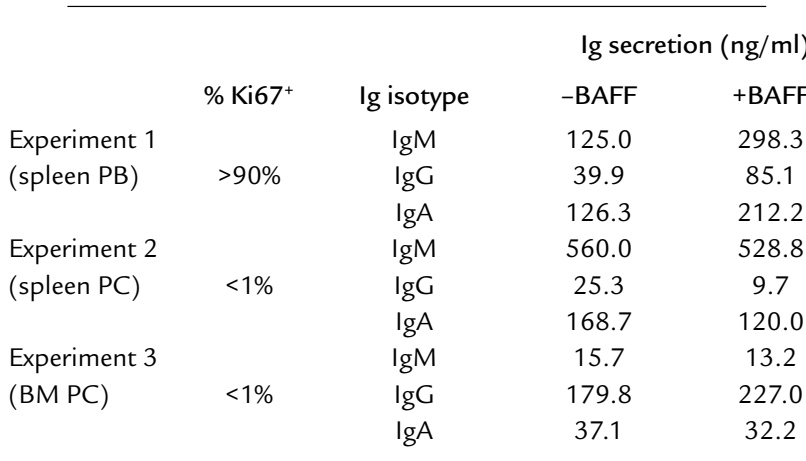

$\mathrm{CD} 38^{++} \mathrm{CD} 20^{+/-}$cells $\left(5 \times 10^{3}\right.$ to $\left.10 \times 10^{3}\right)$ from human spleens (experiments 1 and 2 ) or BM (experiment 3 ) were isolated by cell sorting and were cultured for 4-5 days in media containing IL-2/IL-10 in the absence or presence of soluble BAFF. The proportion of cells expressing Ki67 was determined prior to culture. Levels of secreted IgM, IgG, and IgA were determined by Ig heavy chain-specific immunoassays. Each value represents the mean of duplicate cultures. PB, plasmablast; PC, plasma cell.

$\mathrm{B}$ cells preactivated with the $\mathrm{T}$ cell-derived stimuli CD40L and IL-2/IL-10. In fact, similar numbers of viable cells were recovered from secondary cultures established with IL-2/IL-10 and either CD40L or BAFF. CD40L and BAFF, however, appeared to target different populations of cells through different mechanisms. BAFF specifically enhanced survival of differentiated $\mathrm{CD}^{2} 8^{+}$ISCs by inhibiting apoptosis, while CD40L increased the number of CD38- blasts by promoting further proliferation and reducing apoptosis. The level of $\mathrm{Bcl}-2$ expressed by $\mathrm{CD} 38^{+} \mathrm{B}$ cells generated in the presence of BAFF and IL-2/IL-10 was similar to CD $38^{+} \mathrm{B}$ cells from cultures containing IL-2/IL-10 with or without CD40L (data not shown). Thus, although upregulation of Bcl-2 has been implicated in the antiapoptotic effect of BAFF on murine B cells $(16,46)$, BAFF may mediate its viabilityenhancing effect on human $\mathrm{CD} 38^{+} \mathrm{B}$ cells by modulating expression of pro- and antiapoptotic genes other than Bcl-2, such as Bcl-x, A1 (23), or Blk (47).

BAFF also increased the levels of IgM and IgA, but not IgG, by increasing the number of ISCs generated. This is remarkably consistent with the findings that mice either transgenic for BAFF or injected with BAFF contained significantly increased levels of serum IgM and $\operatorname{IgA}$, but not $\operatorname{IgG}(10,17,23)$, confirming the validity of our in vitro system for examining B cell differentiation. Furthermore, these in vivo and in vitro observations point to the existence of a novel factor that can augment production of IgG by activated mouse and human B cells. The effect of BAFF on human B cells appeared to be mediated by directly stimulating $\mathrm{CD} 38^{+}$ ISCs derived from isotype-switched memory cells, rather than inducing Ig isotype switching by $\operatorname{IgM}^{+}$ memory B cells, as recently proposed for naive B cells (48). Thus, BAFF may be involved in mucosal immune responses characterized by production of high levels of IgA and IgM. Furthermore, the exaggerated humoral immune responses observed in mice administered
BAFF may result from specific enhancement of plasmablast survival in vivo $(10,23)$. Consequently, BAFF may be a therapeutic candidate for treating patients with IgA deficiency in whom B cells are present but fail to secrete IgA $(49,50)$. Since this defect can be partially overcome in vitro by IL-10 (49), it is possible that BAFF and IL-10 might completely restore IgA production in these patients. Furthermore, in human autoimmune diseases, elevated levels of serum BAFF may contribute to the disease not only by breaking tolerance during B cell development (24), but by enhancing survival of plasmablasts in the affected tissues as well.

During differentiation of memory B cells to $\mathrm{CD} 38^{+}$ effector cells, expression of some surface receptors altered. Strikingly, CD40 and BAFF-R were downregulated, while BCMA was induced. Downregulation of $\mathrm{CD} 40$ on CD $38^{+}$ISCs is consistent with previous studies demonstrating reduced expression of CD 40 on plasma cells compared with mature B cells (51). Similarly, the reduced expression of BAFF-R on CD38 ${ }^{+}$ISCs resembled the loss of expression of BAFF-R from primary human $\mathrm{CD} 38^{++} \mathrm{CD} 20^{+/-}$ISCs (data not shown). Our observation that BCMA was weakly expressed on in vitro-derived $\mathrm{CD} 38^{+}$plasmablasts is consistent with earlier reports demonstrating BCMA to be absent or only weakly expressed on pre-B and mature $B$ cell lines, yet present at highest levels on myeloma cell lines (31). Importantly, our data confirm recent studies demonstrating $\mathrm{CD} 38^{+}$plasmablasts generated in vitro from human memory B cells in a manner similar to our cultures (52) express significantly higher levels of BCMA than resting mature B cells. Thus, although BCMA was originally reported to be localized intracellularly (31), our data, together with gene expression studies (52) and studies demonstrating that BCMA can be weakly expressed on the surface of tonsil B cells (13) and stably transfected $293 \mathrm{~T}$ cells $(13,28)$, suggest BCMA can indeed be expressed as a transmembrane receptor. The reduction in the level of $\mathrm{CD} 40$ on in vitro-generated CD $38^{+} \mathrm{B}$ cells provides an explanation for the loss of dependence on CD40L for the continued growth and survival of these cells (36). This loss of CD40L dependency may be compensated by the acquisition of BCMA through which BAFF could elicit downstream signaling pathways independently of BAFF-R $(23,25,28,29)$. Moreover, experiments investigating the effect of the BAFF homologue APRIL lent additional support for a role for BCMA, rather than BAFF-R, in maintaining survival of $\mathrm{CD} 38^{+}$ISCs. The observation that population 2 expresses higher levels of BAFF-R than population 3, yet is only minimally affected by BAFF, is further evidence that BCMA may mediate BAFF signaling on $\mathrm{CD}_{38}{ }^{+} \mathrm{B}$ cells. The possibility, however, that APRIL may exert its effect through a non-BAFF binding-specific receptor cannot be excluded (24). Taken together, these findings point to the possible occurrence of a developmental switch during $B$ cell differentiation whereby BAFF exerts its antiapoptotic effect through distinct counter-receptors. 
Our data suggest that a more detailed analysis of BCMA-deficient mice may reveal a function for this receptor in the effector phase of a humoral immune response. It has been clearly demonstrated that BCMA is dispensable for $B$ cell development $(14,15,32)$, because BAFF- $\mathrm{R}$ is the predominant receptor that delivers survival signals to B cells during ontogeny. None of these studies, however, examined the development of ISCs or plasma cells in BCMA-deficient mice $(14,15$, 32 ). The one study that did examine a T cell-dependent immune response measured the levels of Ag-specific serum IgG1 and found the levels in $\mathrm{BCMA}^{-/-}$mice did not differ significantly from wild-type controls (32). This is perhaps not surprising because the serum level of IgG1 is least affected in BAFF transgenic mice (less than twofold increase). On the other hand, IgA was increased more than 100-fold (17). Taken with our data demonstrating BAFF resulted in increased levels of IgA but not IgG, it is possible that an immune defect against an Ag that induces an IgA response may be affected in BCMA-deficient mice. Alternatively, because the affinity of interaction between BAFF and human BCMA is much greater than that between BAFF and mouse BCMA (15), this receptor may have a distinct function in human B cell differentiation compared with the murine system.

When the effect of BAFF on primary $\mathrm{CD} 38^{++} \mathrm{CD} 2 \mathrm{O}^{+/-}$ $B$ cells was examined, it was found to increase the level of Ig secreted in vitro by plasmablasts but not plasma cells. Thus, BAFF may preferentially contribute to the survival of plasmablasts generated in secondary lymphoid tissues as opposed to terminally differentiated plasma cells. This is reminiscent of a recent study demonstrating the important contribution of BAFF to the survival and subsequent persistence of Ag-specific plasmablasts generated from marginal zone B cells within the murine spleen (46), again highlighting the similarities between data obtained from our in vitro culture system and in vivo models of B cell differentiation. Because human memory B cells localize to the splenic marginal zone $(37,53)$, a similar mechanism may promote the viability of ISCs rapidly generated from human marginal zone/memory B cells following encounters with blood-borne antigens. As plasmablasts undergo further maturation and migration from lymphoid areas to red pulp of spleen and BM, factors such as cytokines and stromal cells located in these areas (54) may substitute for BAFF as a source of survival signals.

BAFF is secreted by monocytes, macrophages, and DCs, and the amount produced is increased by CD40L or IL-10 $(46,48,55,56)$, both of which are required for the generation of $\mathrm{CD}_{38}{ }^{+} \mathrm{B}$ cells from human memory $\mathrm{B}$ cells in vitro (36). In vivo, DCs and CD40L-expressing $\mathrm{CD}^{+}$memory $\mathrm{T}$ cells localize to the outer zone of germinal centers $(57,58)$, where high-affinity Ag-specific B cells undergo selection and differentiation into memory cells or plasma cells (2). Thus, BAFF and IL-10 produced by DCs following interaction with $\mathrm{CD} 40 \mathrm{~L}^{+} \mathrm{T}$ cells may act in concert to facilitate survival and expansion of Ag-specific plasmablasts. The production of IL-10 in such a microenvironment may not only facilitate the generation of CD38 ${ }^{+}$B cells from memory B cells (36), but also increase the concentration of secreted BAFF $(55,56)$, resulting in increased persistence of CD38 ${ }^{+}$ ISCs. Moreover, it has recently been reported that BAFF can induce IL-10 secretion by a human B cell line (59), suggesting an additional mechanism whereby BAFF may promote survival of activated human B cells in the presence of autocrine IL-10.

Our data have shed light on a possible mechanism for the development, as well as treatment, of some human autoimmune diseases. Patients with SLE exhibit elevated serum levels not only of BAFF (19-21), but also IL-10 aberrantly produced by B cells and monocytes (60). Because IL-10 has been found to be a potent inducer of BAFF production by human myeloid cells $(55,56)$, it is possible that elevated levels of serum BAFF in SLE are secondary to the elevated levels of serum IL-10 in these patients. Thus, the combined effect of BAFF and IL-10 on the survival of ISCs in vitro may be recapitulated in vivo in the pathogenesis of some B cell-mediated autoimmune diseases. Consequently, targeting IL-10 (60) in addition to BAFF may have therapeutic benefit for the outcome of SLE, rheumatoid arthritis, and Sjögren's syndrome. In conclusion, our results describing BAFF as a novel survival factor for human differentiated ISCs have wideranging implications for the treatment of human immunodeficiencies as well as autoimmune diseases.

\section{Acknowledgments}

We thank Marylin Kehry and Brian Castle for human CD40L; Rene de Waal Malefyt for human IL-10; Irene Sizing, Fang Qian, Jeff Thompson, Colleen Mullen, Kathy Strauch, and Teresa Cachero for development, production, purification, and validation of the soluble BAFF protein and anti-BCMA, TACI, and BAFF-R $\mathrm{mAb}$; Sandra Gardam for preparation of the APRIL expression plasmid; the Australian Red Cross Blood Service for providing human spleens; Joseph Webster and Tara Macdonald for assistance with cell sorting; and Tony Basten for critical review of this manuscript. This work was supported by the National Health and Medical Research Council of Australia. S.G. Tangye was supported by a U2000 Postdoctoral Fellowship awarded by the University of Sydney. P.D. Hodgkin is a Senior Research Fellow of the National Health and Medical Research Council of Australia. F. Mackay is a Wellcome Trust Senior Research Fellow.

\footnotetext{
1. Van Kooten, C., and Banchereau, J. 1996. CD40-CD40 ligand: a multifunctional receptor-ligand pair. Adv. Immunol. 61:1-77.

2. Liu, Y.J., and Banchereau, J. 1996. The paths and molecular controls of peripheral B-cell development. The Immunologist. 4:55-66.

3. Agematsu, K., et al. 1998. Generation of plasma cells from peripheral blood memory B cells: synergistic effect of interleukin-10 and CD27/CD70 interaction. Blood. 91:173-180.

4. Stuber, E., Neurath, M., Calderhead, D., Fell, H.P., and Strober, W. 1995. Cross-linking of OX40 ligand, a member of the TNF/NGF cytokine family, induces proliferation and differentiation in murine splenic B cells. Immunity. 2:507-521.
} 
5. Aversa, G., Punnonen, J., and de Vries, J.E. 1993. The 26-kD transmembrane form of tumor necrosis factor alpha on activated CD4+ T cell clones provides a costimulatory signal for human B cell activation. J. Exp. Med. 177:1575-1585

6. Garrone, P., et al. 1995. Fas ligation induces apoptosis of CD40-activated human B lymphocytes. J. Exp. Med. 182:1265-1273.

7. Cerutti, A., et al. 1998. CD30 is a CD40-inducible molecule that negatively regulates CD40-mediated immunoglobulin class switching in nonantigen-selected human B cells. Immunity. 9:247-256.

8. Jumper, M.D., Nishioka, Y., Davis, L.S., Lipsky, P.E., and Meek, K. 1995 Regulation of human B cell function by recombinant CD40 ligand and other TNF-related ligands. J. Immunol. 155:2369-2378.

9. Schneider, P., et al. 1999. BAFF, a novel ligand of the tumor necrosis factor family, stimulates B cell growth. J. Exp. Med. 189:1747-1756.

10. Moore, P.A., et al. 1999. BLyS: member of the tumor necrosis factor family and B lymphocyte stimulator. Science. 285:260-263.

11. Shu, H.B., Hu, W.H., and Johnson, H. 1999. TALL-1 is a novel member of the TNF family that is down-regulated by mitogens. J. Leukoc. Biol. 65:680-683.

12. Mukhopadhyay, A., Ni, J., Zhai, Y., Yu, G.L., and Aggarwal, B.B. 1999 Identification and characterization of a novel cytokine, THANK, a TNF homologue that activates apoptosis, nuclear factor-kappaB, and c-Jun NH2-terminal kinase. J. Biol. Chem. 274:15978-15981.

13. Thompson, J.S., et al. 2000. BAFF binds to the tumor necrosis factor receptor-like molecule $B$ cell maturation antigen and is important for maintaining the peripheral B cell population. J. Exp. Med. 192:129-135.

14. Schiemann, B., et al. 2001. An essential role for BAFF in the normal development of B cells through a BCMA-independent pathway. Science. 293:2111-2114.

15. Schneider, P., et al. 2001. Maturation of marginal zone and follicular B cells requires $B$ cell activating factor of the tumor necrosis factor family and is independent of B cell maturation antigen. J. Exp. Med. 194:1691-1697.

16. Mackay, F., et al. 1999. Mice transgenic for BAFF develop lymphocytic disorders along with autoimmune manifestations. J. Exp. Med. 190:1697-1710.

17. Khare, S.D., et al. 2000. Severe B cell hyperplasia and autoimmune disease in TALL-1 transgenic mice. Proc. Natl. Acad. Sci. U. S. A. 97:3370-3375.

18. Gross, J.A., et al. 2000. TACI and BCMA are receptors for a TNF homologue implicated in B-cell autoimmune disease. Nature. 404:995-999.

19. Groom, J., et al. 2002. Association of BAFF/BLyS overexpression and altered B cell differentiation with Sjogren's syndrome. J. Clin. Invest. 109:59-68. doi:10.1172/JCI200214121.

20. Cheema, G.S., Roschke, V., Hilbert, D.M., and Stohl, W. 2001. Elevated serum $B$ lymphocyte stimulator levels in patients with systemic immunebased rheumatic diseases. Arthritis Rheum. 44:1313-1319.

21. Zhang, J., et al. 2001. Cutting edge: a role for B lymphocyte stimulator in systemic lupus erythematosus. J. Immunol. 166:6-10.

22. Batten, M., et al. 2000. BAFF mediates survival of peripheral immature B lymphocytes. J. Exp. Med. 192:1453-1466.

23. Do, R.K., et al. 2000. Attenuation of apoptosis underlies B lymphocyte stimulator enhancement of humoral immune response. J. Exp. Med. 192:953-964.

24. Mackay, F., and Browning, J.L. 2002. BAFF: a fundamental survival factor for B cells. Nat. Immunol. 2:465-475.

25. Shu, H.B., and Johnson, H. 2000. B cell maturation protein is a receptor for the tumor necrosis factor family member TALL-1. Proc. Natl. Acad. Sci. U. S. A. 97:9156-9161.

26. Thompson, J.S., et al. 2001. BAFF-R, a newly identified TNF receptor that specifically interacts with BAFF. Science. 293:2108-2111.

27. Yan, M., et al. 2001. Identification of a novel receptor for B lymphocyte stimulator that is mutated in a mouse strain with severe B cell deficiency. Curr. Biol. 11:1547-1552.

28. Hatzoglou, A., et al. 2000. TNF receptor family member BCMA (B cell maturation) associates with TNF receptor-associated factor (TRAF) 1 TRAF2, and TRAF3 and activates NF-kappa B, elk-1, c-Jun N-terminal kinase, and p38 mitogen-activated protein kinase. J. Immunol. 165:1322-1330.

29. Claudio, E., Brown, K., Park, S., Wang, H., and Siebenlist, U. 2002. BAFFinduced NEMO-independent processing of NF-kappa B2 in maturing B cells. Nat. Immunol. 3:958-965.

30. von Bulow, G.U., and Bram, R.J. 1997. NF-AT activation induced by a CAML-interacting member of the tumor necrosis factor receptor superfamily. Science. 278:138-141.

31. Gras, M.P., et al. 1995. BCMAp: an integral membrane protein in the Golgi apparatus of human mature B lymphocytes. Int. Immunol. 7:1093-1106.

32. Xu, S., and Lam, K.P. 2001. B-cell maturation protein, which binds the tumor necrosis factor family members BAFF and APRIL, is dispensable for humoral immune responses. Mol. Cell. Biol. 21:4067-4074.

33. Yan, M., et al. 2001. Activation and accumulation of B cells in TACI-deficient mice. Nat. Immunol. 2:638-643.
34. Lentz, V.M., Hayes, C.E., and Cancro, M.P. 1998. Bcmd decreases the life span of B-2 but not B-1 cells in $\mathrm{A} / \mathrm{WySnJ}$ mice. J. Immunol. 160:3743-3747.

35. Tangye, S.G., van de Weerdt, B.C.M., Avery, D.T., and Hodgkin, P.D. 2002. CD84 is upregulated on a major population of human memory B cells and recruits the SH2-domain containing proteins SAP and EAT-2. Eur. J. Immunol. 32:1640-1649.

36. Tangye, S.G., Avery, D.T., and Hodgkin, P.D. 2003. A division-linked mechanism for the rapid generation of Ig-secreting cells from human memory B cells. J. Immunol. 170:261-269.

37. Tangye, S.G., Liu, Y.J., Aversa, G., Phillips, J.H., and de Vries, J.E. 1998. Identification of functional human splenic memory B cells by expression of CD148 and CD27. J. Exp. Med. 188:1691-1703.

38. Tangye, S.G., Avery, D.T., Deenick, E.K., and Hodgkin, P.D. 2003. Intrinsic differences in the proliferation of naive and memory human B cells as a mechanism for enhanced secondary immune responses. J. Immunol. 170:686-694.

39. Hasbold, J., et al. 1999. Quantitative analysis of lymphocyte differentiation and proliferation in vitro using carboxyfluorescein diacetate succinimidyl ester. Immunol. Cell Biol. 77:516-522.

40. Arpin, C., et al. 1995. Generation of memory B cells and plasma cells in vitro. Science. 268:720-722.

41. Terstappen, L.W., Johnsen, S., Segers-Nolten, I.M., and Loken, M.R. 1990. Identification and characterization of plasma cells in normal human bone marrow by high-resolution flow cytometry. Blood. 76:1739-1747.

42. Dai, C., and Krantz, S.B. 1999. Interferon gamma induces upregulation and activation of caspases 1,3 , and 8 to produce apoptosis in human erythroid progenitor cells. Blood. 93:3309-3316.

43. Defrance, T., et al. 1987. B cell growth-promoting activity of recombinant human interleukin 4. J. Immunol. 139:1135-1141.

44. Itoh, K., and Hirohata, S. 1995. The role of IL-10 in human B cell activation, proliferation, and differentiation. J. Immunol. 154:4341-4350.

45. Jego, G., et al. 1999. Reactive plasmacytoses are expansions of plasmablasts retaining the capacity to differentiate into plasma cells. Blood. 94:701-712.

46. Balázs, M., Martin, F., Zhou, T., and Kearney, J.F. 2002. Blood dendritic cells interact with splenic marginal zone B cells to initiate T-independent immune responses. Immunity. 17:341-352.

47. Amanna, I.J., Clise-Dwyer, K., Nashold, F.E., Hoag, K.A., and Hayes, C.E. 2001. Cutting edge: A/WySnJ transitional B cells overexpress the chromosome 15 proapoptotic Blk gene and succumb to premature apoptosis. J. Immunol. 167:6069-6072.

48. Litinskiy, M.B., et al. 2002. DCs induce CD40-independent immunoglobulin class switching through BLyS and APRIL. Nat. Immunol. 3:822-829.

49. Briere, F., et al. 1994. Interleukin 10 induces B lymphocytes from IgAdeficient patients to secrete IgA. J. Clin. Invest. 94:97-104.

50. Conley, M.E., and Cooper, M.D. 1981. Immature IgA B cells in IgA-deficient patients. N. Eng. J. Med. 305:495-497.

51. Urashima, M., Chauhan, D., Uchiyama, H., Freeman, G.J., and Anderson, K.C. 1995. CD40 ligand triggered interleukin-6 secretion in multiple myeloma. Blood. 85:1903-1912.

52. Tarte, K., et al. 2002. Generation of polyclonal plasmablasts from peripheral blood B cells: a normal counterpart of malignant plasmablasts. Blood. 100:1113-1122.

53. Dunn-Walters, D.K., Isaacson, P.G., and Spencer, J. 1995. Analysis of mutations in immunoglobulin heavy chain variable region genes of microdissected marginal zone (MGZ) B cells suggests that the MGZ of human spleen is a reservoir of memory B cells. J. Exp. Med. 182:559-566.

54. Kawano, M.M., Mihara, K., Huang, N., Tsujimoto, T., and Kuramoto, A. 1995. Differentiation of early plasma cells on bone marrow stromal cells requires interleukin-6 for escaping from apoptosis. Blood. 85:487-494.

55. Nardelli, B., et al. 2001. Synthesis and release of B-lymphocyte stimulator from myeloid cells. Blood. 97:198-204.

56. Craxton, A., Magaletti, D., Ryan, E.J., and Clark, E.A. 2003. Macrophage and dendritic-cell dependent regulation of human $B$ cell proliferation requires the TNF family ligand BAFF. Blood. 101:4464-4471.

57. Lederman, S., et al. 1992. Molecular interactions mediating T-B lymphocyte collaboration in human lymphoid follicles. Roles of T cell-Bcell-activating molecule ( $5 \mathrm{c} 8$ antigen) and CD40 in contact-dependent help. J. Immunol. 149:3817-3826.

58. Casamayor-Palleja, M., Khan, M., and MacLennan, I.C. 1995. A subset of CD4+ memory T cells contains preformed CD40 ligand that is rapidly but transiently expressed on their surface after activation through the $\mathrm{T}$ cell receptor complex. J. Exp. Med. 181:1293-1301.

59. Xu, L.G., Wu, M., Hu, J., Zhai, Z., and Shu, H.B. 2002. Identification of downstream genes up-regulated by the tumor necrosis factor family member TALL-1. J. Leukoc. Biol. 72:410-416.

60. Beebe, A.M., Cua, D.J., and de Waal Malefyt, R. 2002. The role of interleukin-10 in autoimmune disease: systemic lupus erythematosus (SLE) and multiple sclerosis (MS). Cytokine Growth Factor Rev. 13:403-412. 